\title{
HVMANITAS
}

\section{Memória histórica e narrativa em Heródoto}

Autor(es): $\quad$ Sousa, Paulo Ângelo de Meneses

Publicado por: Faculdade de Letras da Universidade de Coimbra, Instituto de Estudos

URL

persistente: URI:http://hdl.handle.net/10316.2/27517

DOI: $\quad$ DOI:http://dx.doi.org/10.14195/2183-1718_61_5

Accessed : $\quad$ 26-Apr-2023 14:52:08

A navegação consulta e descarregamento dos títulos inseridos nas Bibliotecas Digitais UC Digitalis, UC Pombalina e UC Impactum, pressupõem a aceitação plena e sem reservas dos Termos e Condições de Uso destas Bibliotecas Digitais, disponíveis em https://digitalis.uc.pt/pt-pt/termos.

Conforme exposto nos referidos Termos e Condições de Uso, o descarregamento de títulos de acesso restrito requer uma licença válida de autorização devendo o utilizador aceder ao(s) documento(s) a partir de um endereço de IP da instituição detentora da supramencionada licença.

Ao utilizador é apenas permitido o descarregamento para uso pessoal, pelo que o emprego do(s) título(s) descarregado(s) para outro fim, designadamente comercial, carece de autorização do respetivo autor ou editor da obra.

Na medida em que todas as obras da UC Digitalis se encontram protegidas pelo Código do Direito de Autor e Direitos Conexos e demais legislação aplicável, toda a cópia, parcial ou total, deste documento, nos casos em que é legalmente admitida, deverá conter ou fazer-se acompanhar por este aviso. 
humanitas

\section{Vol. LXI}

IMPRENSA DA UNIVERSIDADE DE COIMBRA

COIMBRA UNIVERSITY PRESS 


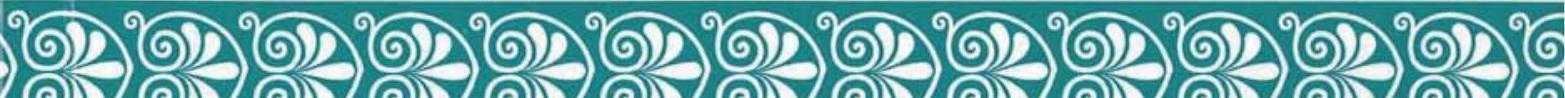

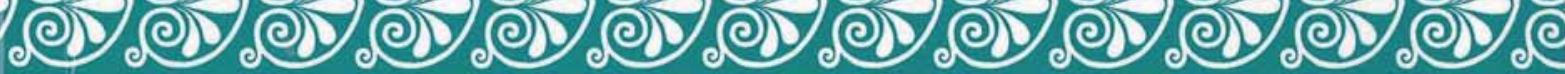

Vol. LXI 


\title{
MEMÓRIA HISTÓRICA E NARRATIVA EM HERÓDOTO
}

\author{
Paulo Ângelo de Meneses Sousa \\ Universidade Federal do Piauí (Brasil) \\ angeloufpi@ig.com.br
}

\section{Resumo}

$\mathrm{O}$ artigo analisa a dualidade helênico/bárbaro subjacente em todo o universo de construção da memória na obra de Heródoto e indica a presença do outro na representação de si mesmo.

Palavras-chave: Heródoto, memória histórica, debate persa.

\section{Résumé}

L'article analyse la dualité hellénique/ barbare sous-jacente dans tous l'univers de construction de la mémoire dans l'oeuvre de Hérodote et indique la présence de l'autre dans la représentation d'elle même.

Mots-clé: Hérodote, mémoire historique, débat perse.

François Hartog defende a hipótese de que os relatos de Heródoto sobre os povos não gregos são como um "espelho" voltado para os gregos para que eles se pensem e compreendam os outros. ${ }^{1}$

Nesses relatos, o objetivo de Heródoto não é saber quem é o melhor, mas compreender como funciona o diferente e o seu estatuto de exilado reforça a sua posição de mediador capaz de adotar uma atitude "imparcial" entre gregos e não gregos.

No proêmio de sua obra, as Histórias, Heródoto expressa o objetivo de suas investigações:

${ }^{1}$ Hartog 1980: 19. 
"Esta é a exposição das investigações de Heródoto de Halicarnasso, para que os feitos dos homens se não desvaneçam com o tempo, nem fiquem sem renome as grandes e maravilhosas empresas, realizadas quer pelos Helenos quer pelos Bárbaros; e sobretudo a razão por que entraram em guerra uns com os outros". 2

Essa declaração de imparcialidade, no entanto, não deve perder de vista o seu "funcionamento etnocêntrico" que é, como observa Hartog, o ponto de partida da construção da memória.

A representação do outro só ocorre dentro de um mesmo sistema e nas Histórias esse sistema é o da cultura grega. Mesmo que Heródoto queira descrever o outro, o "bárbaro", ele só o consegue utilizando as categorias e a lógica de compreensão de um grego do século V a. C.

Segundo Hartog ${ }^{3}$, existe uma lei de oposição binária tão forte nas Histórias - típica do pensamento arcaico grego - que toda vez que Heródoto tenta compreender o outro ele o transforma no duplo inverso e simétrico do modelo grego.

A representação do outro tende a ser dual e assim, até mesmo quando ele descreve dois povos bárbaros um deles tende a se helenizar, pois entre o grego e seu contrário, o "bárbaro", não há lugar para uma terceira possibilidade.

Mas, ainda conforme Hartog, a obra de Heródoto não é "nem deliberadamente nem sistematicamente helenocêntrica" ", sua escritura não é a verdade do discurso do bárbaro nem do grego.

Essas considerações sobre a dualidade helênico/bárbaro que se encontra subjacente em todo o universo de construção da memória na obra de Heródoto, leva-nos a interrogar como ela se apresenta no contexto de memorização histórica da narrativa do célebre "debate persa" presente no livro 3, capítulos 80 a 82 das Histórias.

Um dos procedimentos que Heródoto utiliza para comunicar e traduzir o outro, o bárbaro, nas Histórias é a delegação da palavra aos próprios bárbaros conservando desta forma um espaço considerável à polifonia do

\footnotetext{
${ }^{2}$ Heródoto. Histórias 1. 1-5. Tradução do grego de Ferreira e Silva 1994: 53.

${ }^{3}$ Idem: 227 sqq.

${ }^{4}$ Idem: 371.
} 
texto ao invés de fundá-lo num discurso unificador, procedimento bastante raro nas Histórias. ${ }^{5}$

Entre as formas de delegação da palavra aos bárbaros, de reprodução da enunciação do outro, temos os "discursos relatados" em que o locutor se coloca como "porta-voz" do outro, como no caso da narrativa do debate persa que se apresenta como a reprodução dos discursos pronunciados pelos nobres persas que debateram sobre a melhor forma de governo e 0 regime a ser instituído após a morte de Cambises e a matança dos magos, fato que é datado suposta e provavelmente de $522 \mathrm{a}$. C., enquanto a data de composição dessa narrativa é improvável e se confunde com as datas estabelecidas para os escritos de Heródoto, ou seja, aproximadamente entre 445 e 425 a. C.

A reprodução completa e puramente quantitativa dos discursos não é nem uma possibilidade e nem um ideal historiográfico para os historiadores gregos ${ }^{6}$, na verdade, a prática da reconstituição dos discursos repousa sobre uma seletividade.

Essa característica de seletividade do discurso histórico é inerente ao uso da narrativa e se a escritura histórica de Heródoto é inseparável da narração, ela necessariamente não pode prescindir de uma seleção dos fatos, de um sistema de escolhas, de valorações, elementos que aparecem na reconstituição dos discursos do debate persa.

Analisaremos nesse artigo a construção da memória na narrativa do debate persa destacando também o lugar que ela ocupa nas interpretações historiográficas.

\section{A anomia}

Entre o episódio da matança dos magos (3.79) e o início do debate entre os conspiradores (3. 80.2), Heródoto menciona um interregno de cinco dias que corresponde a uma situação de ausência de lei:

"Assim que acalmou o tumulto e decorreram cinco dias, os que se haviam sublevado contra os Magos deliberaram sobre aquele estado de coisas (...)"7

${ }^{5}$ Sobre a presença das vozes dos outros nas Histórias, vide: Darbo-Peschanski 1987: 113-26.

${ }^{6}$ Cf. Schepens 1975: 84..

${ }^{7}$ Heródoto. Histórias 3. 80.1. Tradução do grego de Pereira 1981: 368. 
Admite-se que esse interregno mencionado por Heródoto, atestado posteriormente também em Sexto Empírico e Sereno ${ }^{8}$, que talvez tenham se fundamentado em Heródoto, corresponde a um costume entre os nobres persas de permanecerem, após a morte do rei, cinco dias sem vigência das leis para destacarem o caráter nefasto da anomia, ou seja, a ausência de leis.

No entanto, para alguns intérpretes esse "costume" persa é empregado por Heródoto num contexto moral e político da tradição grega.

O emprego do sentido de anomia nesse contexto do debate persa, semelhante ao da narrativa da ascensão de Déjoces à realeza dos Medos (1.97), requer um momento histórico em que havia plenamente em curso o sentido de ausência de justiça, violação da lei, doença social, que não pode ser anterior ao início do século $\mathrm{V}$ a. C. e mais precisamente a Hecateu., que serve como referência enunciativa para Heródoto em relação à consignação dos costumes dos povos estrangeiros.

Essa percepção de um quadro institucional definido na narrativa de Heródoto, que leva à colocação do problema do melhor regime de governo para o estabelecimento da eunomia, ou seja, da ordem, levou alguns autores a negarem a origem persa desse debate.

J.E. Powell" interpretou a frase "se a realeza fosse atribuída a um outro dos sete" (3.84.1) como inconsistente no contexto da eleição do rei, como se Otanes, após o fracasso de sua proposta democrática, não houvesse retirado sua candidatura à realeza, tendo em vista que o texto se refere ainda aos sete; o que sugere que a composição desses três capítulos do debate (3.80-83) foi inserida posteriormente numa versão na qual se passava diretamente da magofonia (3.79) à designação de Dario ao trono (3.84).

Heinrich Ryffel ${ }^{10}$ observou também que esse "pretenso costume persa" de cinco dias de interregno desenha exatamente o quadro dos três discursos do debate com seus respectivos intervalos, conduzindo da anomia à monarquia, o que permitiu a Heródoto construir, a partir de uma metabole, uma teoria cíclica das formas de governo.

Mas essa crise de sucessão que antecede o debate persa, por outro lado, permite a Heródoto colocar em confronto, numa perspectiva geral,

\footnotetext{
${ }^{8}$ Apud: Maass 1887: 583.

${ }^{9}$ Apud: Branan 1963: 435.

${ }^{10}$ Ryffel 1949: 63.
} 
duas reflexões sobre os problemas apresentados pela anomia, uma grega e outra oriental.

Segundo Henry Frankfort ${ }^{11}$, a unificação política feita pela monarquia nas civilizações do Oriente próximo representa um fato cultural complexo cujo significado simbólico explica o poder e a permanência dessa instituição como base mesma dessas civilizações.

Na mentalidade desses povos, natureza e sociedade estão integradas, confundidas, e a ordem, tanto no plano da natureza como da sociedade, é colocada sob a dependência do rei, do soberano, cuja função é manter a harmonia dessa integração.

Os mitos orientais, principalmente no Egito e na Mesopotâmia, através de suas cosmogonias, transpõem sobre o plano divino o rei como criador da ordem. Dessa forma, os períodos de crise política ocasionados por uma revolução ou por algum problema na sucessão dos reis correspondem a um abalo na relação entre natureza e sociedade, que é associado a uma imagem mítica de retorno ao caos das origens, que é a ausência de poder e de leis.

O abalo dessa imagem mítica da ordem da natureza e da sociedade presente na mentalidade das civilizações do Oriente próximo coloca em discussão as relações entre a soberania e a ordem do mundo.

Os gregos conheceram também esse tipo de soberania em seu passado, mas tomaram consciência da "crise de soberania" através dodesaparecimento da realeza micênica e criaram um outro espaço social onde o poder não residia mais no palácio, mas na ágora. ${ }^{12}$ Nesse sentido, essa narrativa de Heródoto ao colocar a questão do retorno à ordem, à harmonia da eunomia, através de uma discussão histórica e política, afasta-se consideravelmente das versões míticas de passagem da anomia à monarquia.

Geralmente os relatos míticos de crises políticas vinculadas à passagem da anomia à monarquia correspondem a um combate vitorioso de um deus ou herói mítico contra as forças do mal e da morte presente no mito cosmogônico.

Temos aqui na narrativa de Heródoto um processo consciente e caracterizado de "desmitificação", um esforço para ir além do relato mítico enquanto história divina e encontrar o princípio, a arché, que é agora um problema de ontologia política.

\footnotetext{
${ }^{11}$ Frankfort 1993: 27 sqq.

${ }^{12}$ Esse aspecto é o tema do livro de Vernant 1989.
} 
Mas essa "desmitificação", em nome de uma teoria e filosofia política, não abole o essencial do pensamento mítico que é o prestígio das "origens", além do que a tendência da historiografia antiga foi reduzir os aspectos míticos em humano, mas não aboli-los. ${ }^{13}$

\section{O discurso de Otanes}

Após mencionar o interregno de cinco dias, Heródoto interfere diretamente na narrativa para protestar contra a incredulidade de "alguns Gregos" em relação aos discursos pronunciados no debate persa e reitera esse protesto em outro passo, em 6.43, afirmando que dirá uma coisa surpreendente (megiston thôma) para aqueles dentre os gregos que não aceitam que no debate dos sete persas, Otanes exprimiu a opinião de que os persas deviam "viver em democracia" (dêmokrateesthai).

Trata-se, segundo a maioria dos intérpretes, de uma relação direta com o público grego que reconhece nesse discurso relatado por Heródoto não um discurso persa, mas um discurso grego proveniente da democracia ateniense da segunda metade do século $\mathrm{V}$ a. C., embora com seus arcaísmos.

Desse protesto de Heródoto em 6.43 sobre 3.80, tem-se inferido também que o livro 3 foi escrito e publicado antes do livro 6 e que Heródoto foi adicionando partes desse trabalho após ter sido conhecido pelo público.

Ao enunciar o discurso de Otanes, Heródoto instaura um diálogo com o discurso do receptor grego na medida em que ele se apresenta como um elemento ativo, um contradiscurso, e não apenas como um mero decodificador.

$\mathrm{Na}$ apresentação do discurso do primeiro orador, Heródoto se refere ao interesse de Otanes em colocar "em comum" aos persas as decisões políticas e utiliza o termo "es meson" (80.2) e posteriormente "es to koinon" (80.6).

A expressão es meson pertence ao vocabulário grego do fim do século VI a. C. e tem uma função importante na definição de um pensamento propriamente grego em seus diversos planos.

Heródoto utiliza essa expressão em diversos contextos em sua obra, mas é principalmente no contexto político que ela se faz presente. Assim,

${ }^{13}$ Sobre esse aspecto, vide: Eliade 1991: 100-102 ; Pierart 1983: 47-62. 
o historiador a utiliza para caracterizar as atitudes de Meandro que aboliu a tirania e depôs o poder "no centro" (es meson, 3.142), da mesma forma as atitudes de Cadmo de Cós (7.164) e as reformas de Demônax em Cirene que substituiu a monarquia pela isonomia (4.161).

Mas Heródoto utiliza também essa expressão para caracterizar as deliberações políticas, no sentido de que tudo o que concerne aos interesses do grupo se coloca "no centro", "no meio". ${ }^{14}$

A expressão es meson no contexto do discurso de Otanes tem uma característica pública, aberta, propõe colocar em comum os negócios políticos e não colocar o poder no centro de um círculo que seria o "espaço da palavra" em uma estrutura igualitária, e tem um valor próximo ao de koinon que, embora também seja utilizado em diversas acepções por Heródoto ${ }^{15}$, é empregado no discurso de Otanes no sentido de interesse geral, interesse comum.

Essas duas expressões utilizadas por Heródoto no discurso de Otanes desenham os contornos gerais de um discurso político que, na memória dos gregos, é familiar à democracia grega em seus primórdios, no início do século $\mathrm{V}$ a. C., embora se mantenha aqui também o sentido geral de uma descentralização política proposta por Otanes em relação ao governo de Cambises e do Mago.

Esses contornos gerais do discurso de Otanes vão se definindo em sua crítica à monarquia e tirania e tomam forma mais nítida quando ele menciona as características de sua proposta de governo para os persas.

Heródoto utiliza no discurso de Otanes o termo hýbris, excesso, desmedida, para qualificar as atitudes do governo de um único homem, denominado indistintamente, nesse discurso, de monarquia e tirania.

Essa expressão, largamente utilizada por Heródoto para designar as atitudes dos soberanos bárbaros nas Histórias, é típica do vocabulário da tragédia grega e diversos autore ${ }^{16}$ já notaram a importância da tragédia no nascimento da história, particularmente na obra de Heródoto, que tem como referências enunciativas os relatos trágicos das guerras medas

${ }^{14}$ Por exemplo: $4.97 ; 3.83 ; 4.118 ; 8.21 ; 8.73 ; 7.8$. Sobre esse aspecto, vide: Detienne 1965: 427 sqq.

15 Por exemplo: no sentido de cidade, do Estado $(1.67 ; 5.85 ; 6.14 ; 8.135$; $9.117 ; 3.156 ; 5.109)$ e tesouro público $(6.58 ; 7.144 ; 9.85)$. Cf. Detienne, supra.

${ }^{16}$ Autores de posiçõos diversas como: Robert 1956: 66 sqq ; Hartog 1980: 340 sqq. 
anteriores ao seu, como "A Tomada de Mileto" de Frínico em 493 e "Os Persas" de Ésquilo, em 472 a.C.

A caracterização do poder monárquico ou tirânico no discurso de Otanes é trágica, tendo em vista que o personagem trágico é um ser tomado pela hýbris e o poder monárquico ou tirânico no discurso de Otanes é o próprio lugar da hýbris (80.3).

Segundo Hartog, os esquemas trágicos servem como modelo de inteligibilidade do poder despótico nas Histórias $^{17}$, afirmação que, para o autor, pode ser transposta ao discurso de Otanes que sublinha particularmente uma certa memória grega do político quando entende que o poder monárquico ou tirânico tem por lei a transgressão.

Christine Yerly ${ }^{18}$ afirma que a caracterização da tirania no discurso de Otanes não é fruto de observações diretas e pessoais de Heródoto, mas traduz verdadeiramente o estado da tradição oral do século V a.C.

$\mathrm{O}$ interesse pela figura do tirano na literatura clássica do século $\mathrm{V}$ a.C., num momento em que o tirano está ausente da cena política, ao menos na Grécia continental, representa uma necessidade ideológica da cidade democrática em definir suas normas políticas a partir do contra-exemplo da tirania.

Tanto em Heródoto, como nos trágicos e em Tucídides (cf. 1.18), o tirano aparece como a suma dos componentes negativos de diversos modelos éticos, constituindo-se no inimigo que é posto à margem do sistema político da cidade democrática.

O tirano (e o monarca), como declara Otanes, despreza as regras do sistema cívico, recusa o princípio de igualdade entre os cidadãos que é a isonomia e é responsável pelas desordens sociais e abala os costumes dos antepassados.

A menção de Otanes à hýbris possui também uma relação com toda a tradição ética e política do pensamento grego desde Sólon que propõe a moderação, a sophrosyne, a medida capaz de harmonizar a vida política.

Além dessa qualificação do tirano como um ser hybrístico, excessivo, Heródoto diz também que o tirano (e o monarca) é o anarmostotaton (80.5), ou seja, "o mais desarmonizado".

\footnotetext{
${ }^{17}$ Hartog 1980: 342.

${ }^{18}$ Yerly 1992: 28 sqq.
} 
O emprego figurado desse termo musical para descrever o tirano é bastante significativo e instaura também um diálogo com a tradição grega.

A concepção de alma como uma harmonia e do corpo como um instrumento é muito antiga e tem por base os preceitos pitagóricos sobre a harmonia (a origem e função cósmica da música, fundamentando a ordem do mundo e os seus efeitos sobre a alma), provavelmente de ampla circulação no mundo dórico durante o VII e VI século e aos quais Heródoto deve ter tido fácil acesso. ${ }^{19}$

Um outro diálogo com a memória grega no discurso de Otanes é a utilização do termo phthonos, inveja, como um atributo inato ao homem e que é agravado num regime de governo monárquico ou tirânico.

A obra de Heródoto situa-se dentro da tradição da literatura grega que continua a função de celebrar os grandes feitos humanos, como ele mesmo declara no proêmio de sua obra, e esse discurso de celebração é indissociável de uma atividade de publicidade e de criação de uma glória imortal a esses atos humanos.

O tema da inveja tem particular interesse nessa tradição que remonta a Homero e aos poetas corais como Baquílides e Píndaro, no sentido de que ela representa um dos perigos para a memória e a glória dos heróis.

No discurso de Otanes, a inveja do tirano em relação aos atos dos que estão ao seu redor produz censura e silêncio o que projeta uma sombra sobre o reconhecimento dos grandes feitos humanos.

Mas encontramos também nesse aspecto do discurso de Otanes um tratamento diferenciado do tema da inveja comparado à tradição épica, no qual se percebe também a atitude racionalista de Heródoto ao retirar o conteúdo moral e religioso do tratamento épico da inveja, associada aos deuses, e reduzi-la à antropomorfização em nome de uma filosofia política.

Após as críticas dirigidas à monarquia e tirania, Heródoto menciona as características da proposta de governo de Otanes aos persas que já haviam sido delineadas, em termos gerais, através da expressão es meson (80.2).

Embora Heródoto não mencione no debate nenhuma vez o termo "democracia", é particularmente nas características do governo popular (80.6, plêthos archon) que Otanes se empenhava em instaurar entre os

\footnotetext{
${ }^{19}$ Sobre o conceito de harmonia, vide: Dantas 1987.
} 
persas, que encontramos semelhanças com a democracia ateniense do século V a. C. e, em geral, com o modelo político da Polis.

Aisonomia (80.6) como característica do governo popular mencionado no discurso de Otanes é um termo distinto e historicamente anterior ao de democracia; e, embora exista uma diferença entre esses termos, para grande parte dos intérpretes, nada impede que o termo isonomia seja identificado ao de democracia, tendo em vista que ele representa uma época em que o termo democracia ainda não havia sido popularizado e significava apenas a oposição à tirania. ${ }^{20}$

Considera-se também, por outro lado, que Heródoto emprega o termo isonomia como equivalente a "partilha do poder", referindo-se a uma tradição segundo a qual Otanes defendera o restabelecimento dos direitos que os nobres persas tinham no governo de $\mathrm{Ciro}^{21}$; mas o sentido oligárquico dessa tradição parece incompatível com as características da isonomia mencionadas a seguir por Otanes.

O termo isonomia teria sido talvez o nome que o legislador Clístenes deu às suas reformas iniciadas provavelmente em 508 a.C. em Atenas.

As três características do governo popular de Otanes são típicas das reformas de Clístenes que instauraram os princípios da democracia ateniense e grega. São elas: a eleição pela lei, a responsabilidade dos oficiais pelo exercício dos cargos de magistratura e o controle popular das decisões políticas nas assembléias (80.6).

As reformas de Clístenes, em seus aspectos essenciais, tiveram uma dupla orientação que foram a reorganização do corpo cívico e a criação de novos quadros políticos que modificaram profundamente as instituições existentes.

Elas aumentaram a competência do conselho, da Boulê, que era escolhida através de sorteio pelos demos e tinha a função de exercer o controle sobre os magistrados; e a competência da Ecclesia, assembléia legislativa perante a qual os magistrados prestavam contas de suas atividades.

Segundo José Ribeiro Ferreira, Clístenes com suas reformas - por convicção ou por motivos circunstanciais - "criou de facto as condições materiais para uma soberania efectiva do demos, ao reorganizar, por um lado, de tal modo o corpo cívico que a influência das famílias nobres não pôde mais exercer-se, por terem ficado destruídos os quadros da sociedade

\footnotetext{
${ }^{20}$ Cf. Lévèque e Vidal-Naquet 1984: 28.
}

${ }^{21}$ Evans 1981: 84. 
aristocrática; ao instituir, por outro lado, quadros novos onde essa soberania do povo se poderia na realidade exercer". ${ }^{22}$

A conclusão do discurso de Otanes através da sentença: "Pois é no número que tudo reside" (80.6), lembra um dos pressupostos da democracia grega que é a aplicação da lei da maioria através do voto nas assembléias cívicas, mas também um costume dos persas atestado por Heródoto, segundo o qual a força e o mérito para um persa estão no maior número (1.136).

\section{O discurso de Megabizo}

Ao apresentar o discurso do segundo orador, Heródoto se refere ao interesse de Megabizo em propor a oligarquia para os persas, acolhendo a princípio a crítica de Otanes em relação à monarquia e tirania.

Esse acolhimento de Megabizo da crítica à monarquia feita por Otanes, entendendo também que o poder monárquico tem como característica a hýbris, leva-nos a questionar sobre as relações que as oligarquias persas tinham com a realeza, particularmente no contexto da ascensão de Dario.

Se em termos gerais, o contexto histórico do discurso de Megabizo pode se situar dentro da história da Pérsia, ou seja, que é plausível que as oligarquias tenham questionado o regime monárquico de Cambises e do Mago, no entanto, como nota Pierre Briant ${ }^{23}$, a eliminação do falso Esmérdis e o estabelecimento dos privilégios dos nobres conjurados na nova monarquia não abre uma via para uma dependência durável dos reis em relação às grandes famílias aristocráticas, pelo contrário, a aristocracia persa foi integrada firmemente no campo da política real.

Para $\operatorname{Hartog}^{24}$, a equivalência simbólica entre monarquia e tirania presente no discurso de Megabizo é um indício de que seu discurso se refere ao modelo político da cidade grega, da Polis, "ele fala grego".

A utilização do termo hýbris para qualificar as atitudes do governo de um único homem e do governo popular, reenvia, como já vimos em relação ao discurso de Otanes, a uma memória grega do político.

Particularmente essa memória se torna mais presente para o ouvinte ou leitor grego de Heródoto, na crítica de Megabizo ao discurso de Otanes,

\footnotetext{
${ }^{22}$ Ferreira 1987: 193.

${ }^{23}$ Briant 1990: 103.

${ }^{24}$ Hartog 1980: 332.
} 
pois os ataques à democracia ateniense eram comuns no tempo de Heródoto e mesmo em uma tradição do pensamento político grego.

De fato, a crítica de Megabizo ao governo popular defendido por Otanes implica numa experiência radical da democracia que se assemelha até em seus temas com as experiências democráticas da Grécia do século $\mathrm{V}$ a.C.

O tema da "torrente" utilizado por Megabizo na caracterização do governo popular (81.2), situa-se numa tradição grega que remonta a autores como Homero, Teógnis e Píndaro.

Adrados ${ }^{25}$ nota que o tema da torrente no discurso de Megabizo não apresenta nenhuma originalidade; ele é um tema homérico que foi modificado e adquiriu um sentido político em autores posteriores como Teógnis e Píndaro que o utilizam, assim como Heródoto, para designarem o povo no poder ou a revolução popular segundo uma ótica aristocrática.

A questão da ausência de "instrução", de educação do povo, como objeção dos oligarcas, é também um aspecto teórico que se encontra formulado em discursos oligárquicos dos círculos intelectuais da Grécia.

A argumentação teórica de Megabizo de que o povo é incompetente (achrêiou) para tomar decisões políticas porque ele não é instruído encontra-se formulado em termos semelhantes em Pseudo-Xenofonte ${ }^{26}$, mas deve-se notar um certo anacronismo no discurso de Megabizo em relação aos problemas da atualidade da democracia no tempo de Heródoto.

A crítica de Megabizo não se fundamenta na má fé do povo e aqui ele se diferencia de Pseudo-Xenofonte que em sua crítica à democracia ateniense já estabelecida na segunda metade do século V a.C. insiste na coerência do povo que age conscientemente na defesa de seus interesses através da intolerância política.

$\mathrm{O}$ discurso de Megabizo parece fazer referência ao tempo das guerras medas e colocar em discussão o resultado dessas guerras na memória dos gregos.

Isso fica evidente para o leitor ou ouvinte grego quando Megabizo critica a democracia proposta por Otanes afirmando: "Que pratiquem o governo popular os que querem mal aos Persas" (81.3).

\footnotetext{
${ }^{25}$ Adrados 1965: 8 sqq.

${ }^{26}$ Constituição de Atenas, 1.5. Apud: Schrader 1986: 163 n.406.
} 
Heródoto faz aqui uma inversão do olhar entre o grego e o persa que não deixa de conter uma certa ironia trágica para o público grego, pois os gregos venceram os persas nas guerras medas e se orgulhavam da democracia como símbolo de sua liberdade e superioridade moral em relação aos povos bárbaros.

Segundo Donald Lateiner ${ }^{27}$, a "surpreendente" brevidade do discurso de Megabizo no "debate constitucional" revela a pouca importância da oligarquia na narrativa de Heródoto, o regime mais comumente favorecido nos círculos intelectuais da Grécia.

Talvez sob o conjunto da narrativa das Histórias a oligarquia receba um enfoque secundário e particularmente nesse contexto da ascensão de Dario, deve-se notar que Heródoto faz apenas breves alusões à revolta dos magos e não diz nada sobre as insurreições oligárquicas dos países submetidos ao império persa, ao contrário da inscrição de Behistun de Dario.

Em relação ao espaço e a função do discurso oligárquico de Megabizo no debate persa, é preciso observar que seu discurso incorpora os argumentos de Otanes e se expressa de forma concisa, o que não significa que a economia de argumentos seja indício de sua pouca importância.

Mas, se procede a hipótese de que esse debate aponta para os resultados ideológicos das guerras medas, o discurso oligárquico de Megabizo teria de fato uma função secundária na dualidade helênico/bárbaro do debate que estaria polarizado entre o discurso democrático de Otanes e monárquico de Dario, tendo em vista que no tempo das guerras medas, ideologicamente, o confronto fundamental era entre "despotismo" (monarquia) e "liberdade" (democracia), e nesta luta democracia e oligarquia estavam do mesmo lado contra a monarquia.

\section{O discurso de Dario}

Ao apresentar o discurso do terceiro e último orador, Heródoto se refere ao interesse de Dario em propor a monarquia aos persas, acolhendo a princípio a crítica de Megabizo em relação à democracia proposta por Otanes.

Dario acolhe a crítica de Megabizo feita à democracia, entendendo também que o governo popular tem como característica distintiva a hýbris,

${ }^{27}$ Lateiner 1989: 168. 
o que aproxima seu discurso dos ataques da antiga oligarquia grega à democracia, como já vimos em relação ao discurso de Megabizo.

Esse aspecto antidemocrático do discurso de Dario, que o aproxima de uma certa memória grega, é particularmente importante para questionar a teoria defendida por alguns autores ${ }^{28}$ de que há uma conciliação entre democracia e monarquia nesse discurso, e dessa forma, a posição de Dario refletiria uma mudança na teoria clisteniana do exercício do poder popular que estaria agora associada a um líder, mudança ocorrida durante a ascendência de Péricles ao Estado democrático na Atenas dos anos 40, quando o mesmo foi reeleito estratego durante 14 anos ininterruptamente.

Por outro lado, essa postura antidemocrática de Dario levanta também uma questão em relação a uma certa vertente de interpretação que afirma a incompatibilidade entre a democracia e a concepção de poder autocrático do monarca persa e oriental.

Nels Bailkey ${ }^{29}$ considera que quando Heródoto, nesse discurso de Dario, refere-se à "liberdade" sob um monarca, ele está se referindo a uma espécie de democracia que as sociedades do antigo Oriente conhecem, que é a democracia garantida por uma autoridade central.

A.W. Gomme ${ }^{30}$, embora ache também que Heródoto tem em mente nesse discurso a monarquia persa de Dario, afirma ao contrário, que não há conciliação entre democracia e monarquia, não pode haver meio termo, o monarca é autocrata ou não é.

Um outro aspecto no discurso de Dario que sublinha um diálogo em particular com uma memória grega do político, é a utilização da expressão tôi logôi (82.1), que significa "nas palavras" ou "em teoria", para distinguir os aspectos positivos dos três regimes políticos em debate e afirmar a superioridade da monarquia.

Essa distinção entre teoria e prática das formas de governo encontrase na tradição grega até Platão e Aristóteles.

A monarquia surge como um regime político ideal dentro dessa tradição; e Aristóteles, fazendo eco às palavras de Dario em 3.82.2 referese a homens excepcionais que governam com uma "virtude eminente" e uma capacidade política superior a todos os outros, tal como "um deus entre os homens", afirmando que a superioridade do governo desse homem

\footnotetext{
${ }^{28}$ Cf. Morrison 1970: 76-77 e Connor 1971: 199-206.

${ }^{29}$ Bailkey 1967: 1235.

${ }^{30}$ Gomme 1970: 77.
} 
excepcional, a realeza, não é a das constituições aristocráticas, oligárquicas ou mesmo democrática, todas se reclamam uma superioridade, mas não é a mesma superioridade, ele exerce uma autoridade não sobre uma parte, mas sobre o todo, é uma autoridade suprema e perpétua. ${ }^{31}$

A associação de Dario no debate persa com a imagem de uma monarquia exemplar também se encontra na tradição grega.

Embora com diferenças em seus detalhes, em linhas gerais essa imagem é encontrada em Ésquilo, que faz de Dario em Os Persas (vv. 681-842) um rei superior e intérprete do pensamento divino cujas palavras servem de antídoto às fraquezas e erros de Xerxes.

Platão no Fedro (258c) cita Dario, Licurgo e Sólon como os três legisladores modelos, respectivamente, das constituições monárquicas, aristocrática e democrática; e nas Leis (695c) louva Dario por ter introduzido uma espécie de igualdade já preconizada por Ciro e por seu governo ter se aproximado muito de uma monarquia ideal.

Um outro diálogo com a memória grega é a classificação das formas de governo no passo 82.1 do discurso de Dario.

Essa tríplice classificação de Heródoto das constituições políticas, ou seja, governo popular, oligarquia e monarquia, encontra-se implícita na classificação anterior de Píndaro, em 468 a. C., que se expressa assim: "um homem de palavra leal faz-se valer em todos os países: junto dos tiranos, lá onde reina a multidão impetuosa e nas cidades que governam os sábios" (2 Pítica $86-88){ }^{32}$

Mas essa classificação de Píndaro não possui ainda terminologia própria e nem estabelece de forma sistemática as características essenciais dessas constituições.

Esse estudo e classificação de Heródoto das formas de governo, é considerado o primeiro na literatura grega e a base de toda a teoria política grega e da tradição ocidental antiga, medieval e moderna. ${ }^{33}$

Alguns autores discutem se esses três modelos implicam, já nesse discurso de Heródoto, três ou seis formas de governo que corresponderiam às suas variantes positivas e negativas.

${ }^{31}$ Aristóteles. A Política 1284 a 10; 1268 a 16.

${ }^{32}$ Apud: Romilly 1959: 81.

${ }^{33}$ Sobre o lugar dessa classificação de Heródoto na teoria política ocidental, vide: Bobbio 1992: 39-43. 
Jacqueline de Romilly ${ }^{34}$ nota que o hábito (sofista) de Heródoto de distinguir em cada um dos regimes dois aspectos, um bom e um mal, poderia fornecer as bases de uma classificação em seis regimes, mas não existe nenhum texto até Platão sugerindo que esse passo foi dado, ao contrário, as classificações correntes repousam sempre em três regimes.

H. Ryffel ${ }^{35}$ afirma que nessa teoria de Heródoto já está implícita uma classificação em seis constituições, tendo em vista que os três regimes são encarados sob a forma do melhor possível (82.1) o que significa distinguir os três bons dos três maus regimes.

As terminologias políticas eram ainda flutuantes na época que Heródoto compôs a sua obra, e talvez seja demasiado afirmar que nessas três formas fundamentais de governo Heródoto já sentisse as suas alterações para lhes atribuir nomes distintos, que de fato não se encontram na obra do historiador, ou seja, da democracia para a oclocracia, da oligarquia para a aristocracia e da monarquia para a tirania, distinção que só virá a ser completamente delineada no século IV em Aristóteles (A Política 3.5) e depois esquematizada nessas duas séries correspondentes em Políbio (6.3.6).

A argumentação subsequente de Dario em relação às qualidades de um governante único retomam as acusações de Otanes em relação à monarquia entendida também como tirania e instaura um diálogo com uma memória grega.

Quando Heródoto focaliza as qualidades do monarca - um homem de entendimento superior, que governa o povo de modo irrepreensível e melhor guarda em segredo as decisões contra o inimigo (82.2) - ele é particularmente contrário a uma certa mentalidade grega pouco monárquica e acostumada com as conotações negativas da palavra tirano na tragédia grega e com o elogio à liberdade política da democracia.

Essa referência de Dario à necessidade de guardar em segredo as decisões contra o inimigo está em consonância com o contexto da narrativa de Heródoto de ascensão de Dario, fazendo alusão ao seu primeiro argumento contra a posição de Otanes e em favor do ataque instantâneo aos magos antes que o plano fosse delatado (cf. 3.71.4); mas também coloca em discussão duas posturas distintas em relação à concepção de autoridade política presente entre os gregos e persas.

\footnotetext{
${ }^{34}$ Romilly 1959: 82sqq.

${ }^{35}$ Ryffel 1949: 65 n.96.
} 
A abertura e o caráter público dos negócios políticos proposto por Otanes (80.2), pode ser vista dentro de uma concepção grega de autoridade política e remete ao "universo espiritual da polis" 36 onde a exigência de uma plena publicidade dada às manifestações mais importantes da vida social se opõe aos processos secretos de decisão política.

O fechamento e o caráter privado das decisões políticas proposto por Dario, pode ser visto dentro de uma concepção oriental de autoridade política e remete aos processos secretos de decisões políticas tomadas no recesso do palácio e que constituem o privilégio exclusivo dos basileus.

Outro aspecto que sublinha um diálogo com a memória grega é a imagem da evolução das formas de governo apresentada no discurso de Dario (82.3-4).

A imagem da evolução das formas de governo como um fluxo encontra-se também na tradição grega, como por exemplo, no Anônimo de Jâmblico (cap.7), em Platão (Político 291 c - 292 d ; República 8) e em Aristóteles (A Política 3).

$\mathrm{O}$ entendimento de que democracia e oligarquia engendram stasis, guerra civil, e instauram a monarquia, pode ser inserido dentro da história persa de passagem da anomia à monarquia confirmada pelo próprio contexto da ascensão de Dario, ainda que a passagem da democracia à monarquia seja mais difícil de se encontrar na história persa.

Esse raciocínio de que a monarquia nasce da anomia encontra-se também na narrativa da ascensão de Déjoces à realeza dos Medos (1.96 sqq.), o que mostra que se trata de um raciocínio familiar ao pensamento político de Heródoto.

Mas esse fluxo pode ser inserido numa tradição grega de passagem da democracia e oligarquia, não para monarquia, mas para tirania.

Alguns autores ${ }^{37}$ consideram que é mais a experiência grega do que a persa que Heródoto tem em mente ao compor esse passo do discurso de Dario.

O primeiro momento de ascendência da monarquia no discurso de Dario, é a descrição dos fracassos da oligarquia que resulta em facções (stasies, 82.3) rivalizando-se pelo poder e que fazem emergir a monarquia que vem por fim a essas dissensões, raciocínio que, para esses autores,

\footnotetext{
${ }^{36}$ Vernant 1989: 34.

${ }^{37}$ Cf. por exemplo: Gomme 1970: 77 e Hartog 1980: 332.
} 
corresponde à experiência grega da origem da tirania e será um lugar comum da retórica e da teoria política grega do século IV a. C.

Esse raciocínio de que através das dissensões faccionais entre oligarcas nasce a tirania, também se encontra na narrativa da história de Psístrato em 1.59-64 onde se encontra sete vezes a palavra stasies, o que mostra mais uma vez que se trata de um raciocínio familiar ao pensamento político de Heródoto.

O segundo momento de ascendência da monarquia no discurso de Dario é a descrição dos fracassos da democracia que resulta em associações conspiratórias para prejudicarem o Estado e que fazem emergir um homem que vem por fim a esses atos e por isso é admirado (thômazetai, 82.4) pelo povo e proclamado monarca, raciocínio que, para esses autores, corresponde a um famosíssimo lugar comum da teoria política grega e em particular da crítica antidemocrática, que é a passagem da demagogia à tirania.

Para uma determinada corrente de interpretação $0^{38}$, nesse ponto Heródoto não está refletindo uma teoria monárquica persa, nem defendendo a monarquia no horizonte constitucional grego, pois na Grécia não existia uma "teoria monárquica".

Na experiência política grega, pelo menos até Platão, não se vislumbra a passagem da democracia à monarquia, por outro lado, no desenvolvimento constitucional da Pérsia, Heródoto, conforme essa corrente de interpretação, deve estar pensando em Péricles como "defensor do povo" (prostas tis tou dêmou, 82.4), expressão que encontra paralelo em Tucídides ao se referir a Péricles como "defensor da cidade" (Tucídides 2.65.5), embora deva-se observar que para Tucídides a prostas tis de Péricles não é um pródomo da tirania.

Outros autores ${ }^{39}$ defendem que nessa passagem da oligarquia e democracia para monarquia está implícito a teoria da metabole politeion ("mudança das constituições"), que corresponde a uma concepção cíclica das formas de governo que remonta, na tradição grega, aos trabalhos de Sólon sobre a boa ordem política, a eunomia.

Segundo essa interpretação, mesmo que essa mudança das constituições na narrativa de Heródoto venha parar na monarquia, o que é apenas uma confirmação dos fatos da história persa, tendo em vista que foi Dario quem subiu ao trono, está expressa claramente a idéia de que as formas de

\footnotetext{
${ }^{38}$ Cf. por exemplo: Stroheker Apud: Apfell 1957: 14.

${ }^{39}$ Cf. Ryffel 1949: 14 sqq.
} 
governo se deterioram naturalmente e inevitavelmente, não apenas em condições especiais, dando lugar a outras formas de governo, o que caracteriza uma teoria cíclica.

Para outros autore ${ }^{40}$, no entanto, não se pode afirmar que no discurso de Dario, Heródoto já concebesse a noção de uma teoria da metabole politeion como tal, ou seja, como uma mudança cíclica e inevitável das constituições, o que não exclui a possibilidade de uma teoria mais simples ou uma "fenomenologia" que explicasse apenas alguns processos de mudanças das formas de governo que poderiam ser encontradas na experiência grega.

Stewart Flory ${ }^{41}$ aponta um vínculo entre o discurso de Dario no "debate constitucional", a história de Déjoces (1.96 sqq.) e a de Psístrato (1.59 sqq.), afirmando que encontramos aí um padrão do pensamento político de Heródoto que associa tirania e monarquia à boa ordem e liberdade com desordem.

A ascensão de Dario, como a de Déjoces e Psístrato têm em comum o fato de que elas põe fim a um período de instabilidade ou de governo irregular. O que Heródoto enfatiza nessas histórias são as atrações e os perigos da autonomia e enuncia claramente a idéia de que o governo de um único homem é o melhor.

A argumentação subseqüente de Heródoto no discurso de Dario relativa ao conceito de liberdade, eleuthería (82.5), estabelece também um diálogo com uma memória grega.

Retornamos aqui mais uma vez aos resultados ideológicos das guerras medas na mentalidade dos gregos do século $\mathrm{V}$ a.C.

As palavras de Dario em relação à liberdade estão em consonância com uma certa representação política que associa os bárbaros ao despotismo e os gregos à liberdade, simbolizada pela democracia, tendo em vista que o argumento de Dario omite as questões de administração interna do Estado, substâncias das críticas de Otanes à monarquia/tirania, e considera liberdade apenas como a nação livre do dominador estrangeiro, via segundo a qual os persas, sob a monarquia de Ciro, realizou a sua libertação.

Alguns autores ${ }^{42}$ consideram que o argumento melhor construído no debate persa é o de Otanes, seu ataque à tirania é mais profundo e não é

\footnotetext{
${ }^{40}$ Por exemplo: Lasserre 1976: 78 n.41 e Strom 1951: 146.

${ }^{41}$ Flory 1987: 120 sqq.

${ }^{42}$ Mossé 1979: 20 e Lateiner 1989: 169 e 274 n.20.
} 
respondido pelo "frágil" discurso de Dario que faz apenas um "silêncio discreto" sobre esse caso, embora que essa crítica seja melhor aplicada às tiranias gregas do que à monarquia teocrática persa.

Mas se a crítica de Otanes em relação à monarquia é de que ela "abala os costumes ancestrais" (80.5), o argumento de Dario é construído de forma a identificar monarquia com esses costumes, ou seja, com o respeito ao patrious nomos enquanto patrious politeía dos persas.

Nesse aspecto, temos aqui em Heródoto um diálogo com um tema fundamental do pensamento grego que é a doutrina do nomos.

A palavra nomos, que aparece 12 vezes na obra de Heródoto, tem o significado usual de costume ou tradição associada à lei, mas na verdade comporta uma variada gama de sentidos. ${ }^{43}$

Nomos inclui costumes no sentido antropológico moderno da palavra, costumes de casamento, ritos de morte e sepultamento, costumes alimentares e religiosos $(1.216 ; 2.98$ - 100); compreende crenças religiosas (1.35; 1.49), táticas de guerra (5.97), dialeto ou linguagem de uma nação (2.42.4) e também leis que são estabelecidas por um legislador $(1.29 ; 1.65)$, leis não escritas $(5.42 .2 ; 7.2)$ além de outros aspectos como a constituição de um país ou forma de governo $(4.161 ; 5.92)$.

Os nomoi em Heródoto fazem parte das causas históricas, conforme Evans eles " são o guia principal atrás dos atos dos homens, e determinam o que o homem fará numa dada situação. Dessa forma, os persas atacando a Grécia, agem de acordo com seus costumes-leis, e os Gregos se defendendo, agem de acordo com os seus".

É a partir da segunda metade do século V a.C. que encontramos uma forte crítica à observância ao nomos, fundamento até então do helenismo, percebendo também que ele pode ser tirânico, principalmente após a conquista da liberdade, como é o caso do imperialismo ateniense acerca do qual Heródoto tem uma postura crítica ${ }^{44}$, e assim a questão da reconciliação entre lei e liberdade ocupará os debates políticos.

Expressão de uma crise que abala a sociedade grega no fim do século $\mathrm{V}$ a.C., o pensamento dos sofistas representa uma espécie de contraponto à concepção de nomos como expressão da justiça. Antifonte considerava que o respeito ao nomos, à lei, tem como conseqüência o encorajamento da

\footnotetext{
${ }^{43}$ Cf. Evans 1965: 142-153.

${ }^{44}$ Harvey 1966: 254-55.
} 
hipocrisia e da dissimulação, já Hípias chama a lei "o tirano dos homens"45, entendendo que o nomos não é expressão da justiça, mas uma violência contra a physis, a natureza. ${ }^{46}$

Esse recurso aos "costumes dos ancestrais" (patrious nomos) presente nos discursos de Otanes e Dario recorda também um debate presente nas últimas décadas do século $\mathrm{V}$ a.C. e pelo decorrer do século IV em Atenas sobre a "Constituição dos ancestrais" (patrious politeía), ou seja, o debate sobre o retorno de Atenas ao regime de seus ancestrais a partir da idéia do "fracasso" da democracia ocasionada pela derrota ateniense na Sicília entre $415-413$ a.C. ${ }^{47}$

\section{Conclusão}

Dada a característica antitética subjacente ao relato dos discursos do debate persa, perceptível na manifestação do narrador que opõe no início da narrativa gregos e persas, ele nos remete à própria intenção de Heródoto de preservar a memória dos gregos e bárbaros expressa no proêmio de sua obra.

Todo o enunciado de Heródoto nessa narrativa está associado a uma memória discursiva grega inscrita na história que serve como referência para verificar os efeitos de memória que sua enunciação produz e que constitui, ao nosso ver, um campo de discussão sobre as relações entre memória histórica e narrativa.

É nesse sentido que a nossa análise procurou avançar mostrando como essa narrativa de Heródoto dialoga com o horizonte do mundo histórico da Grécia do século V a.C. projetado sobre a história aquemênida.

Como conclusão que abre questões, talvez se possa repropor a análise desse texto de Heródoto não apenas em termos de um diálogo com a memória histórica helênica, mas também avaliando a influência da tradição Oriental nessa narrativa.

Conforme Helmut Apffel ${ }^{48}$ podemos contar certamente com uma tradição persa subjacente a esse debate; isto é apoiado pela firme conexão

${ }^{45}$ Platão. Protágoras 337 c-d. Tradução do grego de Teixeira 1986: 119.

${ }^{46}$ A discussão entre natureza (physis) e lei (nomos) era comum entre os sofistas, sobre esse ponto vide: Guthrie 1995: cap. II.

${ }^{47}$ As tradições desse debate foram mais tarde recolhidas e transmitidas por Aristóteles na sua obra A Constituição de Atenas.

${ }^{48}$ Apfell 1957: 22 e 96. 
entre a discussão e a narração principal e também pelos diversos argumentos de origem persa nessa narrativa.

Para esse autor, não é mais apropriado investigar esse debate dentro de uma "literarização" radical em um espaço exclusivamente helênico, quer dizer, sub specie sophistarum, já que os pesquisadores tornaram conhecidos textos persas antigos que deram nova luz à relação entre a Hélade e o Oriente.

\section{Bibliografia}

\section{Edições, traduções e comentários do "debate persa"}

Erodoto, Le Storie. Libro 3 - La Persia. A cura di David Asheri e Silvio M. Medaglia e traduzione di Augusto Fraschetti., Milano: Fondazione Lorenzo Valla, 1990.

Heródoto, Historia. Libros 3-4. Traducción e notas Carlos Schrader, Madrid: Gredos, 1986.

Heródoto, Histórias. Livro 3. Tradução do grego de Maria de Fátima Silva e Cristina Abranches, Lisboa: Edições 70, 1997.

Heródoto. Livro 3, cap. 80-83. Tradução do grego de Pereira, M. H. R. (1981), "O mais antigo texto europeu de teoria política", Nova Renascença 1: 364-370.

\section{Outras obras e artigos}

AdRADOs, F. R. (1965), "El tema del torrente en la literatura griega arcaica y classica", Emérita XXXIII: 7-14.

Apfell, H. (1957), Die verfassungsdebatte bei Herodot (3, 80 - 82). Dissertation Erlang.

Aristóteles, A Constituição de Atenas. Tradução do grego, notas e comentários de Francisco Murari Pires. São Paulo: Hucitec, 1995. A Política. Tradução de Nestor Silveira Chaves. Rio de Janeiro: Ediouro, 1995.

Bailkey, N. (1967), "Early mesopotamian constitutional development", AHR 72: 1211- 1236.

Branan, P. T. (1963), "Herodotus and history. The constitutional debate preceding Darius'accession ", Traditio 19: 427-438. 
Briant, P. (1990), "Hérodote et la societé perse", in O. Reverdin (ed.), Hérodote et les peuples non grecs. Genéve: Fondation Hardt, 69113.

Boвbio, N. (1992), A teoria das formas de governo. Brasília: UnB.

Connor, W. R. (1971), The new politicians of fifth century Athens. Princepton.

Dantas, P. (1987), Harmoniai and Nomoi. RHBNC: University of London.

Darbo-Peschanski, C. (1987), Le discours du particulier. Paris: Seuil.

Detienne, M. (1965), "En Grèce Archaïque: Géometrie, Politique et Société", Annales ESC 3: 425-441.

Eliade, M. (1991), Mito e Realidade. São Paulo: Perspectiva.

Evans, J. A. S. (1981), "Notes on the debate of the Persian Grandees in Herodotus 3.80-82", QUCC 36: 79-84. . (1965), "Despotes Nomos", Athenaeum IV: 142-153.

FERreira, J. R. (1987), “As Reformas de Clístenes”, Biblos LXIII: 179-199.

FLORY, S. (1987), The arcaic smile of Herodotus. Wayne State University Press: Detroit.

Frankfort, H. (1993), Reys y Dioses. Madrid: Alianza Editorial.

Gomme, A. W. (1970), "Pericles Monarchos", JHS: 77.

Guthrie, W. K. C. (1995), Os Sofistas. São Paulo: Paulus.

Hartog, F. (1980), Le miroir d'Hérodote. Paris: Gallimard.

Harvey, F. D. (1966), "The political sympathies of Herodotus", Historia 15: 254-55.

HeróDOto. Histórias - Livro 1. Tradução do grego de José Ribeiro Ferreira e Maria de Fátima Silva. Lisboa: Edições 70, 1994.

LASSERRE, F. (1976), "Hérodote et Protagoras: Le débat sur les constitutions", MH 33: 65-84.

Lateiner, D. (1989), The historical method of Herodotus. Toronto: University of Toronto Press.

LÉVÈQue, P. e Vidal-Naquet, P. (1984), Clistène L'Athénien. Paris: Mácula.

MaAss, E. (1887), “Zur Geschichte der griechischen Prosa 2: Herodot und Isokrates", Hermes 22: 581-595.

Morrison, J. S. (1970), "Pericles Monarchos“, JHS: 76-77.

Mossé, C.(1979), Histoires des doctrines politiques en Grèce. Paris: PUF. Pierart, M. (1983), "L’historien Ancien face aux mythes et aux légendes", LEC 1, LI: 47- 62. 
Platão, A República. Tradução do grego de Maria Helena da Rocha Pereira.

Lisboa: Fundação Calouste Gulbenkian, 1990, $6^{\text {a }}$. ed. , Político. Tradução do grego de Jorge Paleikat e João Cruz Costa, in Platão - Diálogos. Os Pensadores. São Paulo: Abril Cultural, 1972.

, Protágoras. Tradução do grego de Eleazar Magalhães Teixeira. Fortaleza: UFC, 1986.

Robert, F. (1956), "Histoire et tragédie au V siècle", IL 2: 66-70.

Romilly, J. (1959), "Le classement des constitutions d'Hérodote a Aristote", REG 72: 81- 99.

Ryfrel, H. (1949), Metabole Politeion. Bern.

SchePens, G. (1975), "L'idéal de l'information complete chez les historiens grecs", REG LXXXVIII 419-423: 81-93.

Strom, H. (1951), "Metabole Politeion", Gnomon XXII: 144-149.

Vernant, J. P. (1989), As origens do pensamento grego. Rio de Janeiro: Bertand Brasil.

YerLy, C. (1992), "Figures du tyran archaïque: entre le monstre et le sage", EL 2: 3-32. 